\title{
Dürfen Schüler therapeutisch arbeiten?
}
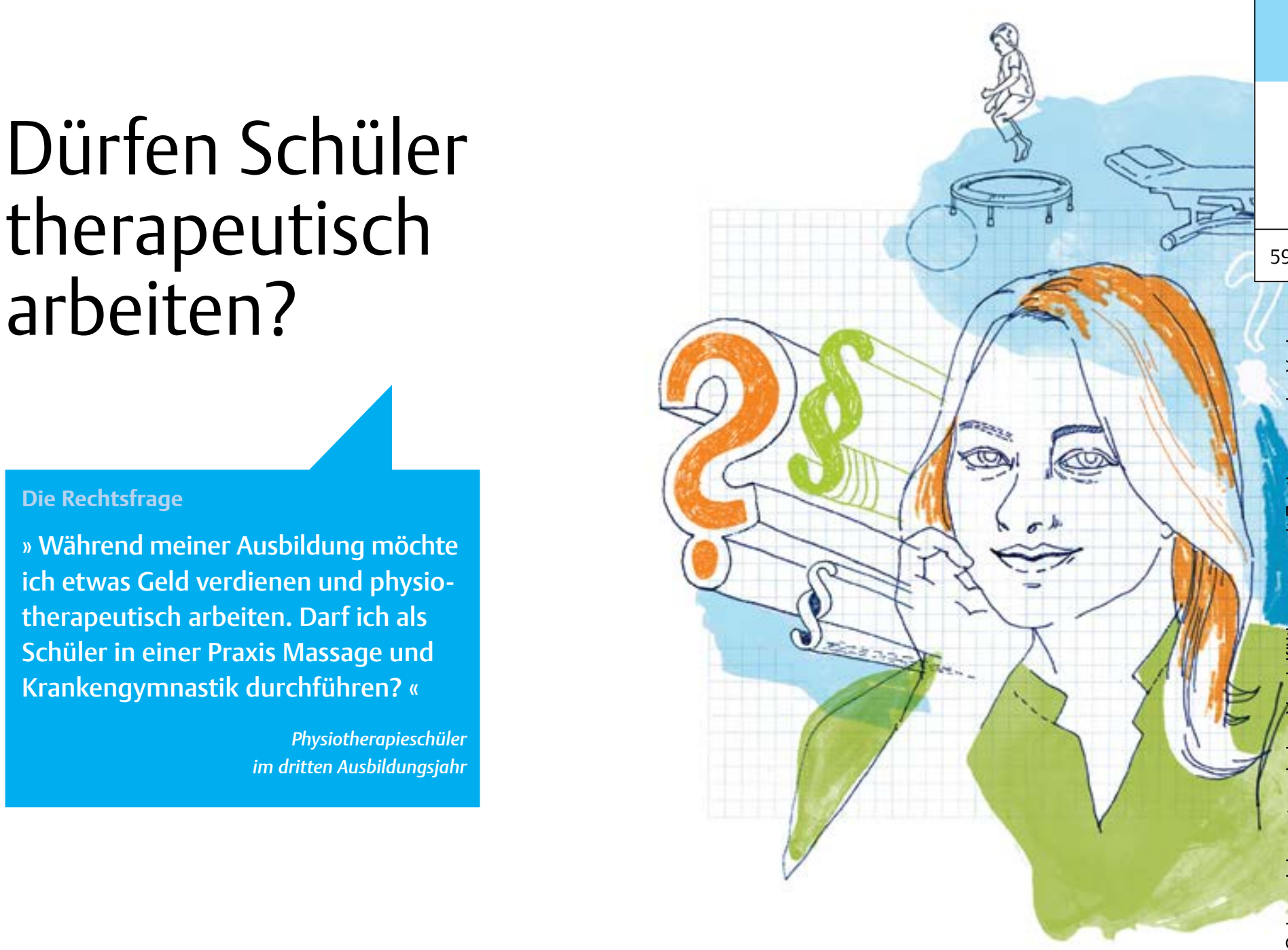

Die Antwort unseres Experten

Die Berufsausübung der Masseure und Physiotherapeuten ist im Masseur- und Physiotherapeutengesetz geregelt. Danach darf als Masseur und medizinischer Bademeister sowie als Physiotherapeut nur arbeiten, wer die Erlaubnis dafür hat. Sie wird erteilt, wenn man die erforderliche Ausbildung absolviert und die staatliche Prüfung bestanden hat. Darüber hinaus darf man sich nichts zuschulden kommen lassen, was einen beruflich unzuverlässig erscheinen ließe. Man muss gesundheitlich geeignet sein und über die erforderlichen beruflichen Kenntnisse in deutscher Sprache verfügen. Als Physiotherapieschüler befinden Sie sich noch in der Ausbildung und verfügen noch nicht über die staatliche Prüfung.

Von physiotherapeutischen Tätigkeiten kann man die Tätigkeiten im Rahmen der praktischen Ausbildung abgrenzen. Hier werden Auszubildende unter Aufsicht und unter der Verantwortung eines Ausbilders tätig. Daneben könnten sie ohne den erforderlichen Abschluss lediglich Hilfsarbeiten in einer Praxis verrichten, für welche die Ausbildung zum Physiotherapeuten nicht erforderlich ist.

Ein weiteres Problem stellt sich für den Praxisinhaber, wenn er die erbrachten physiotherapeutischen Leistungen gegenüber den gesetzlichen Krankenkassen abrechnen will. Als Heilmittel abrechenbar ist die Leistung nämlich nur, wenn sie auch von einer entsprechend ausgebildeten Person oder unter ihrer Anleitung und Aufsicht erbracht wurde. Das wäre bei Ihnen nicht der Fall. Außerdem geht der Praxisinhaber ein hohes zivilrechtliches Haftungsrisiko ein, wenn er die Leistungen nicht durch eine Fachkraft erbringen lässt und Behandlungsfehler auftreten.

Karsten Bossow $\rightarrow$ Wirft auch Ihr Berufsalltag rechtliche Fragen auf? Dann schreiben Sie eine E-Mail an Simone.Gritsch@thieme.de.

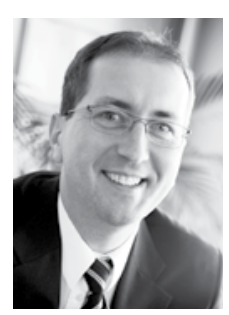

Karsten Bossow ist seit 1999 Rechtsanwalt. Seit 2003 ist er Fachanwalt für Arbeitsrecht und seit 2010 für Medizinrecht. 